\title{
Platinum/ceria/alumina catalysts on microstructures for carbon monoxide conversion
}

\section{G. Germani, P. Alphonse, M. Courty, Y. Schuurman-and C. Mirodatos}

Institut de Recherches sur la Catalyse, CNRS, 2 Avenue Albert Einstein, 69626 Villeurbanne, France

CIRIMAT, UMR-CNRS 5085, Université Paul Sabatier, 118 route de Narbonne, 31062

Toulouse Cedex 04, France

\begin{abstract}
$\underline{\text { Abstract }}$
Platinum/ceria/alumina catalysts have been prepared by a sol-gel method and coated in the microchannels of stainless steel platelets. These catalysts are very active for the water-gas shift reaction between 300 and $400{ }^{\circ} \mathrm{C}$. Moreover, they are non-pyrophoric and thus well suited for the purification of hydrogen for PEM fuel cells. The obtained coatings show good adherence and catalytic activity. The influence of the amount of platinum and ceria as well as the effect of a binder on the catalytic performance has been investigated. The samples have been characterized before reaction by XRD, SEM and by $\mathrm{N}_{2}$ adsorption measurements. The kinetics, free from internal diffusion limitations, over these thin films have been described by a power law rate equation. An activation energy of $86 \mathrm{~kJ} / \mathrm{mol}$ has been found and at $260{ }^{\circ} \mathrm{C}$ the TOF corresponds to $0.6 \pm 0.1 \mathrm{~s}^{-1}$ for all investigated samples. The superior activity of the platelets compared to the powder samples is attributed to the diffusion limitations inside the powder pellets. Thus catalysts deposited on microstructured platelets lead to a better platinum utilization.
\end{abstract}

Keywords: Water-gas shift; Hydrogen purification; Microreactors; Kinetics; sol-gel; Catalyst coating 
1. Introduction

2. Experimental

2.1. Experimental set-up

2.2. Synthesis of sols

2.3. Coating of the microstructured plates

2.4. Characterization of catalysts

3. Results

3.1. Activity tests

3.2. X-ray diffraction

3.3. Electron microscopy

3.4. Porosity and surface area by gas adsorption

4. Discussion

5. Conclusions

Acknowledgements

References

\section{Introduction}

The generation of high-purity hydrogen is required for efficient operation of the solid polymer electrolyte membrane (PEM) fuel cell. This hydrogen can be produced from hydrocarbon fuels or alcohols by a reforming step. This typically yields a mixture of hydrogen, carbon monoxide, carbon dioxide and steam. The carbon monoxide level must be reduced below $50 \mathrm{ppm}$ to avoid poisoning of the fuel cell electrodes [1]. This is generally accomplished in several steps that might include the high and low temperature water-gas shift (HT-/LT-WGS) as well as a preferential oxidation step. The WGS converts $\mathrm{CO}$ into $\mathrm{CO}_{2}$ by the reaction with water over a suitable catalyst and provides additional hydrogen. The reaction generally attains thermodynamic equilibrium. Two types of catalysts are commonly used in industry: a FeCr based catalyst for HT-WGS and a CuZn catalyst for LT-WGS. The volume of the WGS takes a considerable part of the overall fuel processor due to the thermodynamic constraint to operate at the lowest possible temperatures to achieve high conversions. At these low temperatures most catalysts are not very active. In view of new applications such as on board hydrogen generation for PEM fuel cells, more active catalyst formula are required for down-scaling the reformer, together with fast response, long catalyst lifetime and nonpyrophoric materials [2].

Several new WGS catalysts have been reported in the literature such as $\mathrm{Au} / \mathrm{Fe}_{2} \mathrm{O}_{3}[3]$ and [4], $\mathrm{Au} / \mathrm{CeO}_{2}$ [4] and [5], $\mathrm{Ru} / \mathrm{ZrO}_{2}$ [6], $\mathrm{Rh} / \mathrm{CeO}_{2}$ [7] and $\mathrm{Pt} / \mathrm{CeO}_{2}$ [4], [8], [9] and [10] as 
promising catalysts for fuel cell applications as they are highly active in the range of 250$400{ }^{\circ} \mathrm{C}$ and they are non-pyrophoric. However these catalysts are expensive and optimum use of the precious metal is required. Metal microstructured platelets which allow a precise temperature control and the use of thin catalyst layers that lead to high efficiency could meet the on board reformer requirements as new compact and efficient systems [11]. This paper reports on the development of platinum/ceria/alumina catalysts on microstructured platelets for the WGS reaction. The focus is on developing methods that lead to strongly adhesive and stable catalyst layers on stainless steel plates that retain their high activity. Sol-gel methods were selected for this purpose, on the basis of literature results [12] and lab experience. It is shown that this strategy leads indeed to a better usage of the precious metal.

\section{Experimental}

\subsection{Experimental set-up}

The used microstructured platelets are made of stainless steel and have the following dimensions: $50 \mathrm{~mm} \times 50 \mathrm{~mm} \times 1 \mathrm{~mm}$, containing 49 channels $400 \mu \mathrm{m}$ deep and $600 \mu \mathrm{m}$ wide. The steel grade was ASTM 316Ti (DIN 1.4571). They are placed together with some filler plates inside a stainless steel housing. Care was taken to assure that no bypassing of the gas occurred. In the initial experiments bypassing was revealed by the fact that the thermodynamic equilibrium was not attained at higher temperatures. By using the proper filler platelets this issue has been solved. The housing is sealed with graphite rectangular seals. This housing allows a proper gas distribution through the microstructured platelets. Moreover, it can be opened up after reaction and the platelets can be taken out for analysis purposes. The heating is provided by means of six $500 \mathrm{~W}$ heating cartridges inserted into the housing body. The reactor temperature was measured with a thermocouple located in the reactor housing close to the exit. Preliminary measurements showed that the temperature deviation between the inlet and outlet is less than $2^{\circ}$.

Mass flow controllers regulate the gas flows. Water is dosed by a syringe pump, vaporized and then mixed into the gaseous reactants stream.

The product gas analysis is carried out at the reactor exit by an Inficon Transpector CIS2 mass spectrometer. 
Prior to the activity test, each batch of platelets was reduced in a flow of $10 \% \mathrm{H}_{2}$ in argon (total flow $=200 \mathrm{~N} \mathrm{ml} / \mathrm{min}$ ). The temperature was raised from 25 to $450{ }^{\circ} \mathrm{C}$ at a rate of $4{ }^{\circ} \mathrm{C} / \mathrm{min}$, and then kept at $450{ }^{\circ} \mathrm{C}$ for $30 \mathrm{~min}$. The reactor temperature is lowered to $200{ }^{\circ} \mathrm{C}$ in a flow of $10 \% \mathrm{H}_{2}$ in argon. The flow is then switched to pure argon and subsequently to the reactive flow with a feed composition of: $32.2 \% \mathrm{H}_{2}, 9.6 \% \mathrm{CO}, 8.4 \% \mathrm{CO}_{2}, 23.0 \% \mathrm{H}_{2} \mathrm{O}, 26.8 \%$ Ar with a total flow of $200 \mathrm{~N} \mathrm{ml} / \mathrm{min}$. Such feed composition is typical of the outlet of a gasoline autothermal reformer, after steam addition for favouring the WGS.

Two platelets of each batch were used for the activity tests. The exact amount of catalyst that could be coated on each platelet depended on the batch, but was about $100 \mathrm{mg}$ on average. In one case a powder catalyst was used for comparison. The catalyst was sieved to obtain the particle fraction between 200 and $300 \mu \mathrm{m}$. This powder catalyst was tested in a $6 \mathrm{~mm}$ inner diameter quartz tube under similar conditions as the platelets.

Both carbon and hydrogen balances were established that both amounted to $101 \pm 1 \%$. At temperatures above $350{ }^{\circ} \mathrm{C}$ traces of methane were detected, its concentration amounted to maximum $0.05 \%$ at $420{ }^{\circ} \mathrm{C}$. In the current paper and for all calculations the methane concentration has been neglected.

\subsection{Synthesis of sols}

The synthesis of the alumina sols, precursor of the catalyst, is based on the method originally proposed by Yoldas [12]. The first step of the process was the hydrolysis of aluminum alkoxide (in this work, aluminum tri-sec-butoxide, $\mathrm{Al}\left(\mathrm{OC}_{4} \mathrm{H}_{9}\right)_{3}$-Acros Organic) at $85^{\circ} \mathrm{C}$ in large excess of water $\left(\mathrm{H}_{2} \mathrm{O} / \mathrm{Al}=100\right)$. This gives an aluminium hydroxide slurry that was subsequently peptized, at $85^{\circ} \mathrm{C}$, to a clear sol by addition of nitric acid $\left(\mathrm{HNO}_{3} / \mathrm{Al}=0.07\right)$.

The required amount of the platinum precursor $\left(\mathrm{H}_{2} \mathrm{PtCl}_{6}, 6 \mathrm{H}_{2} \mathrm{O}-\right.$ Prolabo Analytical $)$ was dissolved in the water used for the hydrolysis whereas the ceria precursor $\left(\mathrm{Ce}\left(\mathrm{NO}_{3}\right)_{3} \cdot 6 \mathrm{H}_{2} \mathrm{O}\right.$ - Acros Organic $)$ - dissolved in the minimum amount of water - was added after peptization. Yoldas [12] suggested that the peptization can be done by an acid solution containing the water soluble salt. But it has been observed that, under these conditions, the peptization becomes very slow and several days are needed to obtain a clear sol. Therefore we have preferred to add the solution of the ceria precursor after the complete peptization. 
Several sols have been synthesized, in order to prepare catalysts containing about 1 or 2 wt.\% of Pt (referred to as P1 or P2) and 10 and 20 wt.\% of $\mathrm{CeO}_{2}$ (referred to as $\mathrm{C} 1$ or $\mathrm{C} 2$ ). To some of the sols a polyvinyl alcohol (Rhodoviol ${ }^{\mathrm{TM}} 4 / 125$ - Prolabo) has been added (referred to as R). This polymer can adsorb at the surface of the colloïdal particles, thus stabilizing the sol.

The diluted sols prepared according to this procedure are suitable only for the synthesis of thin layers $(<1 \mu \mathrm{m})$. For the synthesis of thicker layers that were needed to attain the required amount of catalyst (about $100 \mathrm{mg}$ of catalyst per microstructured platelet), sols have been prepared loaded with catalyst powder made by firing the same sol at $500{ }^{\circ} \mathrm{C}$.

These loaded sols contained $10 \mathrm{wt} . \%$ of catalyst powder mixed with Rhodoviol ${ }^{\mathrm{TM}}$ (5 wt.\%). The mixture was ball milled for $30 \mathrm{~min}$. These loaded sols allowed preparing thick layers with a good quality of coating because very little shrinkage occurs during drying. The synthesis parameters are summarized in Table 1 for the various samples.

Table 1.

Summary of the synthesis parameters

\begin{tabular}{|l|l|l|l|l|l|}
\hline Sample reference & $\mathbf{P t}(\mathbf{w t .} \%)$ & $\mathrm{CeO}_{\mathbf{2}}(\mathbf{w t} . \%)$ & Rhodoviol in sol (wt.\%) & Reduction under $\mathrm{H}_{2}$ \\
\hline P1C2 & 0.8 & 19.6 & 5 & \\
\hline P1C2R & 0.8 & 19.6 & 15 & No \\
\hline P1C1 & 0.9 & 9.8 & 5 & No \\
\hline P2C1 & 1.7 & 10.7 & 5 & No \\
\hline P2C1H & 1.7 & 10.7 & 5 & No \\
\hline
\end{tabular}

\subsection{Coating of the microstructured plates}

The first step was the conditioning of the steel in order to ensure the best adhesion between the layer and the substrate. In this operation the plates were immersed into an alkaline cleaner (Turco ${ }^{\mathrm{TM}} 4181$ ) at $75^{\circ} \mathrm{C}$ for $30 \mathrm{~min}$. Then they were rinsed with water in an ultrasound bath. Finally they were dried and heated in air at $200{ }^{\circ} \mathrm{C}$ for $2 \mathrm{~h}$. 
The coating was performed by tape casting in such a way that the sol remains only inside the microchannels. After coating, the plates were dried overnight at room temperature. The final step was a calcination in air at $500{ }^{\circ} \mathrm{C}$ for $2 \mathrm{~h}$.

\subsection{Characterization of catalysts}

The crystal structure was investigated by powder X-ray diffraction (PXRD). Data were collected on a Seifert 3003TT $\theta-\theta$ diffractometer in the Bragg-Brentano geometry, using filtered $\mathrm{Cu} \mathrm{K} \alpha$ radiation and a graphite secondary-beam monochromator. Diffraction intensities were measured by scanning from $5^{\circ}$ to $90^{\circ}(2 \theta)$ with a step size of $0.02^{\circ}(2 \theta)$.

Scanning electron microscopy (SEM) analyses were done on a JEOL JSM-6700 (equipped with a field emission gun). Transmission electron microscopy (TEM) analyses were done on a JEOL 2010. A small amount of sample powder was put in ethanol and dispersed in an ultrasound bath during $1 \mathrm{~min}$. Then the carbon-coated grid was dipped in the suspension and allowed to dry at room temperature.

The nitrogen adsorption-desorption isotherms and the krypton adsorption isotherms were determined at $77 \mathrm{~K}$ by volumetric method with a Micromeretics ASAP 2010.

\section{Results}

\subsection{Activity tests}

Table 2 gives the characteristics of the different samples that have been tested. The amounts of both ceria and platinum measured on the samples $\mathrm{P} 2 \mathrm{C} 1$ and $\mathrm{P} 2 \mathrm{C} 1 \mathrm{H}$ are somewhat lower than the amount deduced from the preparation method. The platinum dispersion of the $\mathrm{P} 2 \mathrm{C} 1$ sample has been measured by $\mathrm{H} 2$ chemisorption according to the protocol outlined in [13]. The dispersion amounted to 58\%. The five different samples have been tested for their catalytic activity with the flow composition given above, typical of a reformate gas at the outlet of an autothermal gasoline reformer.

Table 2.

Summary of the key parameters of the microstructured samples as well as the powder 


\begin{tabular}{|c|c|c|c|c|c|}
\hline Platelet & $\begin{array}{l}\text { Catalyst mass for two } \\
\text { platelets (mg) }\end{array}$ & $\begin{array}{l}\mathrm{CeO}_{2} \\
(\%)\end{array}$ & $\begin{array}{l}\mathbf{P t} \\
(\%)\end{array}$ & $\begin{array}{l}\text { Rate at } 260{ }^{\circ} \mathrm{C} \\
\left(\mathrm{mmol} / \mathrm{s} \mathrm{kg}_{\text {cat }}\right)\end{array}$ & $\begin{array}{l}\text { TOF }\left(s^{-1}\right) \text { at } \\
260{ }^{\circ} \mathbf{C}^{\underline{\underline{b}}}\end{array}$ \\
\hline $\mathrm{P} 2 \mathrm{C} 1$ & 252 & $8.3^{\mathrm{a}}$ & $1.4^{\mathrm{a}}$ & 34 & 0.7 \\
\hline $\mathrm{P} 2 \mathrm{C} 1 \mathrm{H}$ & 226 & $8.3^{\underline{\mathrm{a}}}$ & $1.4^{\mathrm{a}}$ & 25 & 0.5 \\
\hline $\mathrm{P} 1 \mathrm{C} 1$ & 164 & 9.8 & 0.9 & 14 & 0.5 \\
\hline $\mathrm{P} 1 \mathrm{C} 2$ & 200 & 19.6 & 0.8 & 15 & 0.6 \\
\hline $\mathrm{P} 1 \mathrm{C} 2 \mathrm{R}$ & 200 & 19.6 & 0.8 & 16 & 0.7 \\
\hline Powder & - & $8.3^{\mathrm{a}}$ & $1.4^{\mathrm{a}}$ & 26 & 0.5 \\
\hline
\end{tabular}

${ }^{a}$ Measured by atomic absorption spectroscopy, all other values have been deduced from the preparation method.

${ }^{\mathrm{b}}$ Based on the amount of Pt as determined from the preparation method and assuming a dispersion of $58 \%$.

The carbon monoxide conversions as a function of the temperature for the different microstructures are shown in Fig. 1. From $250{ }^{\circ} \mathrm{C}$ onwards a rapid increase of the carbon monoxide conversion is observed for all samples that levels off at higher temperatures to attain the thermodynamic equilibrium conversion. The measured conversions cannot be compared directly to rank the platelets in activity, due to the different amounts of catalyst per platelet, but the use of the same volumetric flow rate. However, a comparison of the initial reaction rates can be performed at low conversions. Therefore the initial reaction rates have been calculated at $260{ }^{\circ} \mathrm{C}\left(X_{\mathrm{CO}}<6 \%\right)$ and are reported in Table 2. The data of the $\mathrm{P} 2 \mathrm{C} 1$ sample have been modeled according to a power law rate equation. The model consists of a one dimensional plug flow reactor that explicitly takes into account the mass and heat balance in the axial direction as well as over the catalyst layer/particle at each grid point. The least square non-linear regression analysis of the integral experimental carbon monoxide conversions is based on a Marquardt optimization routine. All this is implemented in a FORTRAN code (for more details on the model and the used correlations see [14] and [15]).

$$
\begin{aligned}
& r_{c o}(\operatorname{mol} / \mathrm{skg})=(13 \pm 1) \times 10^{6} \exp \left(\frac{-(860 \pm 15) \times 10^{3}}{R T}\right) \\
& \times P^{(0.3 \pm 0.1)} P^{0.49 \pm 01} P^{(-0.45 \pm 006)} P^{(-012 \pm 065)}(1-\beta)
\end{aligned}
$$




$$
\begin{gathered}
\beta=\frac{P_{\mathrm{H}_{2}} P_{\mathrm{CO}_{2}}}{K_{\mathrm{Qq}_{\mathrm{q}}} P_{\mathrm{CO} \mathrm{H}_{2} \mathrm{O}}} \\
K_{\mathrm{eq}}=\exp \left(\frac{4577.8}{T}-4.33\right)
\end{gathered}
$$

Fig. 1. Conversion of carbon monoxide over the different microstructured samples as a function of temperature (note that the lines are just a guide to the eye).

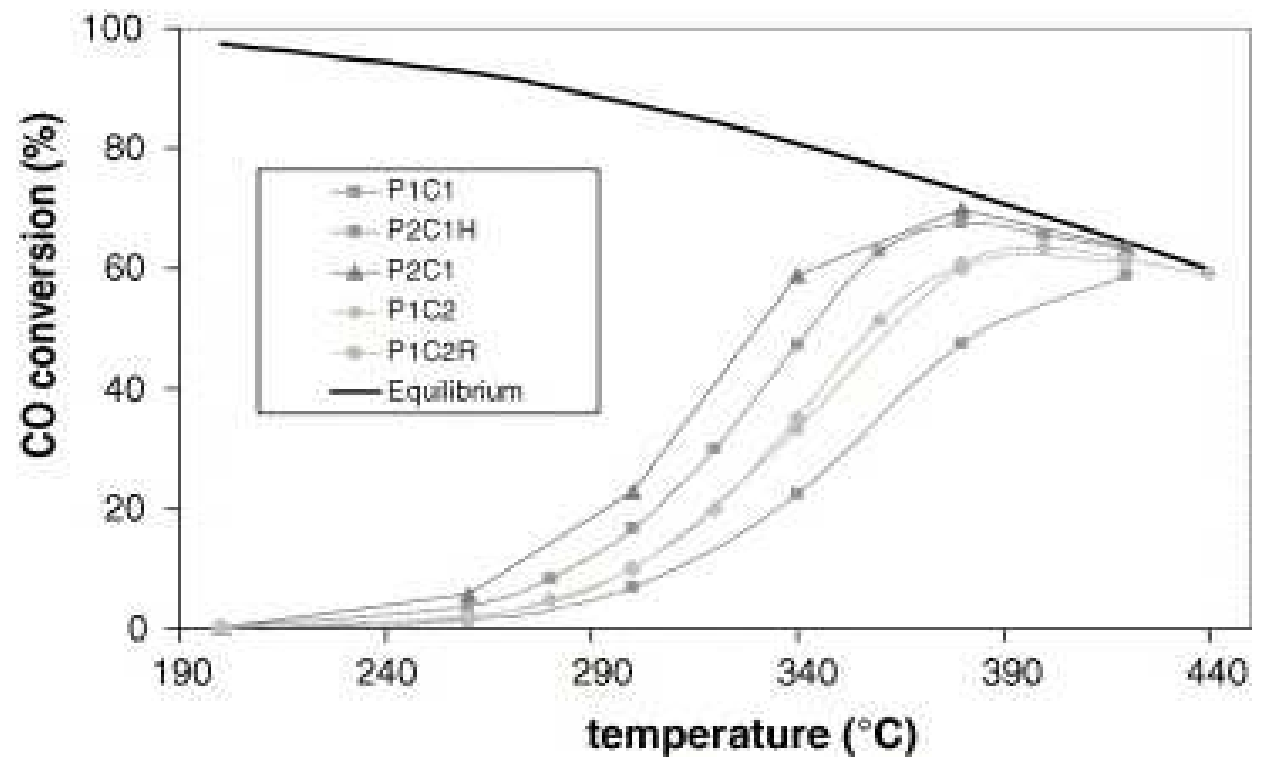

The 95\% confidence intervals on the estimated parameters are reported in Eq. (1). The fit of the data as a function of temperature is shown in Fig. 2. The reaction orders of carbon monoxide and hydrogen were determined by separate experiments over different samples by varying the partial pressures of carbon monoxide and hydrogen (data not reported here). Only the pre-exponential factor and the activation energy were estimated from the data presented in Fig. 1. An adequate description of the data over the entire temperature range is observed. By only adjusting the relative activity, a similar fit of all the other data can be obtained. Using this rate equation, the activity of the other samples can be estimated by correcting for the different catalyst amounts. It was found that the activity of the different samples did not vary more than $\pm 15 \%$, similar to that of the TOF (turnover frequency) at $260{ }^{\circ} \mathrm{C}$ reported in Table $\underline{2}$. 
Fig. 2. Comparison between the experimental data (symbols) and the model calculations (line) for the P2C1 sample.

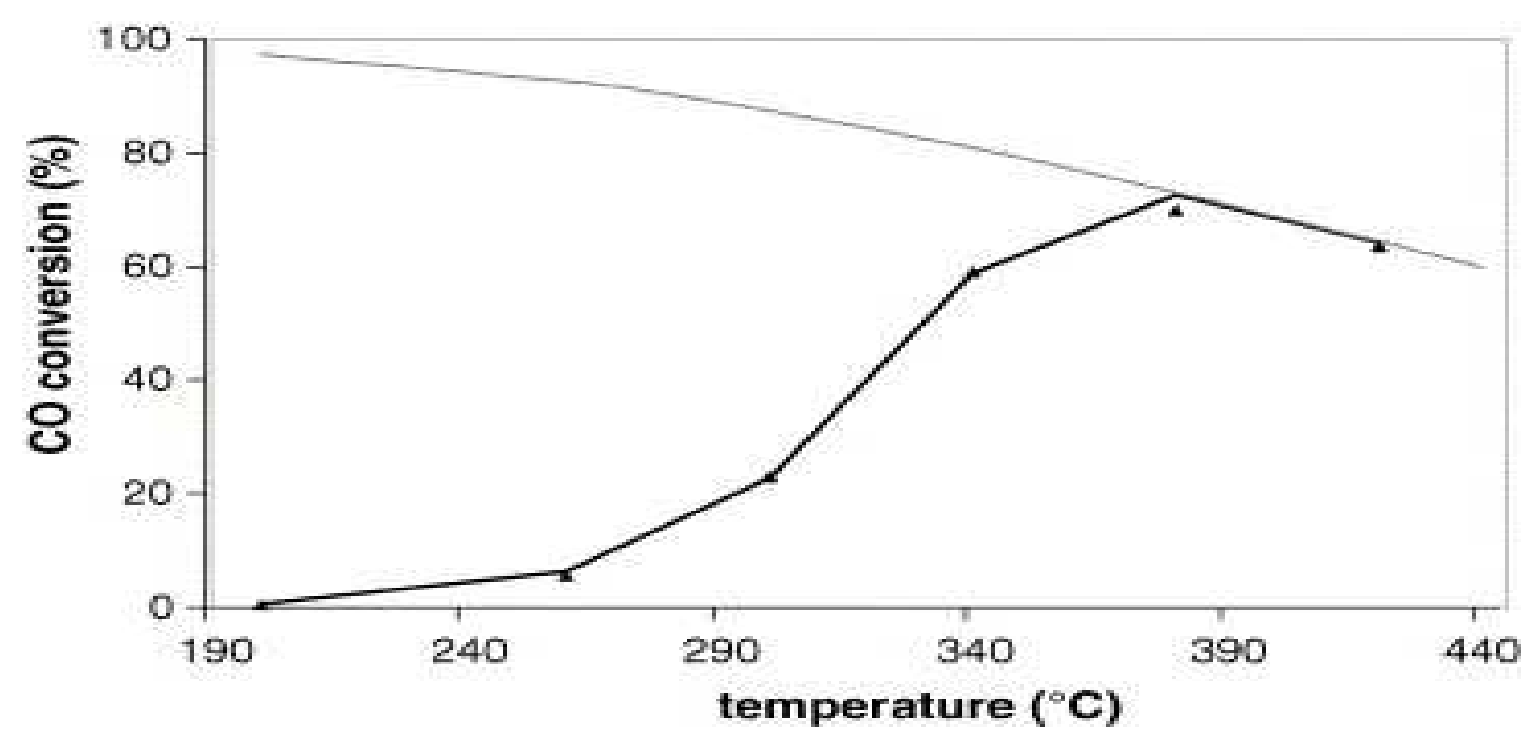

The sample P2C1 was also tested in the form of a powder, in order to see how the coating procedure influences the activity. Therefore $252 \mathrm{mg}$ of powder (equivalent to two platelets of the stated sample) where loaded into a quartz tube reactor with an inner diameter of $6 \mathrm{~mm}$, and tested under the same conditions as for the platelets. Fig. 3 compares the carbon monoxide conversion levels for the microstructured platelet and powder catalyst. The graph shows a much lower activity for the powder sample compared to the platelet. Again the relative activity could be calculated by using the rate Eq. (1) and amounted to approximately $60 \%$ compared to that of the platelet.

Fig. 3. Comparison between the samples P2C1 deposited on stainless steel microstructured platelets (grey) and in powder form (black). Symbols: experimental data, solid lines: model calculations. 


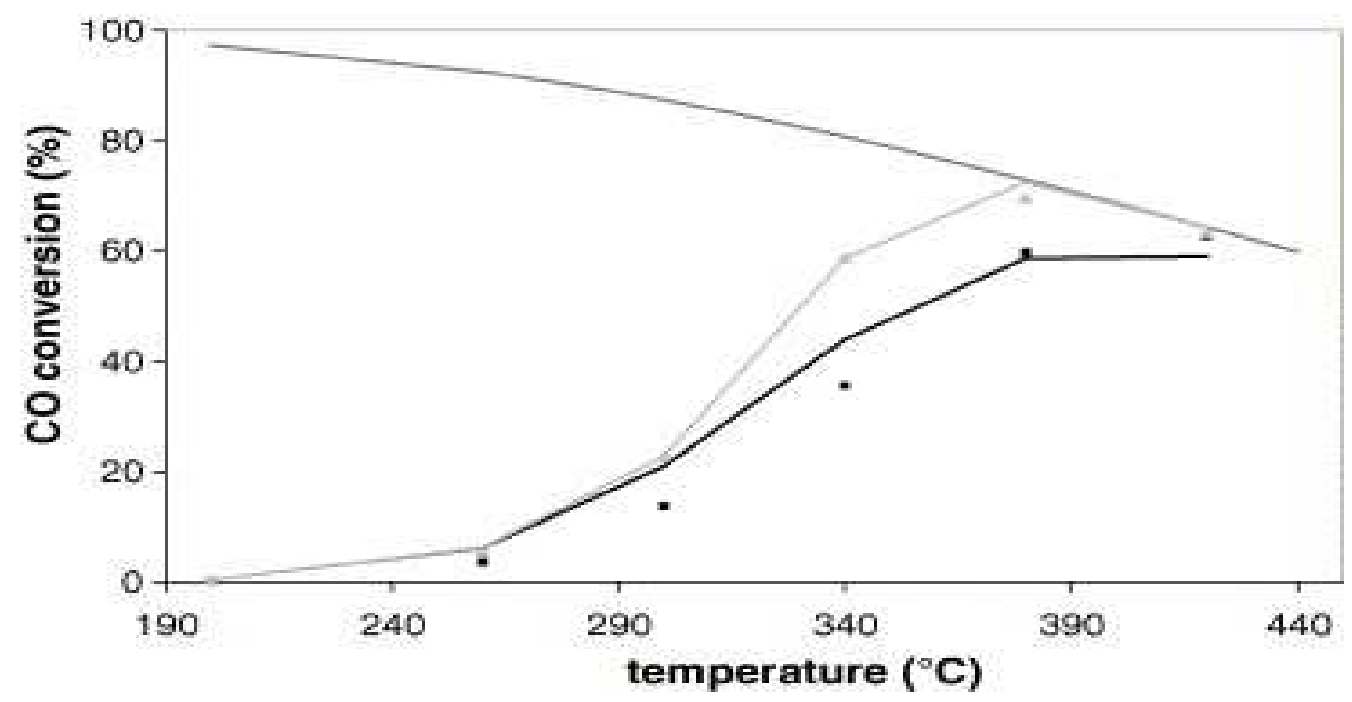

3.2. X-ray diffraction

Powder X-ray diffraction patterns of platinum/ceria/alumina catalysts are reported in Fig. 4. To show the effect of the ceria, a pattern of pure $\gamma$-alumina has been added. The addition of ceria to the alumina renders the oxide more amorphous (the presence of ceria delays the crystallization of alumina) and the lines of cubic $\mathrm{CeO}_{2}$ (calculated pattern at the bottom of the graph) are visible. The lines of $\mathrm{CeO}_{2}$ almost have disappeared after a reduction of the catalyst in hydrogen at $500{ }^{\circ} \mathrm{C}$ (Fig. 5). From this pattern it is difficult to know if metallic platinum was formed after reduction, as the line $\left(\begin{array}{lll}1 & 1 & 1\end{array}\right)$ of metallic platinum can hardly be identified.

Fig. 4. Powder XRD patterns of the platinum/ceria/alumina catalysts calcined at $500{ }^{\circ} \mathrm{C}$ in air $\left(\lambda_{\mathrm{Cu}}=0.154184 \mathrm{~nm}\right)$. Calculated lines of cubic $\mathrm{CeO}_{2}$ have been added at the bottom of the figure. 


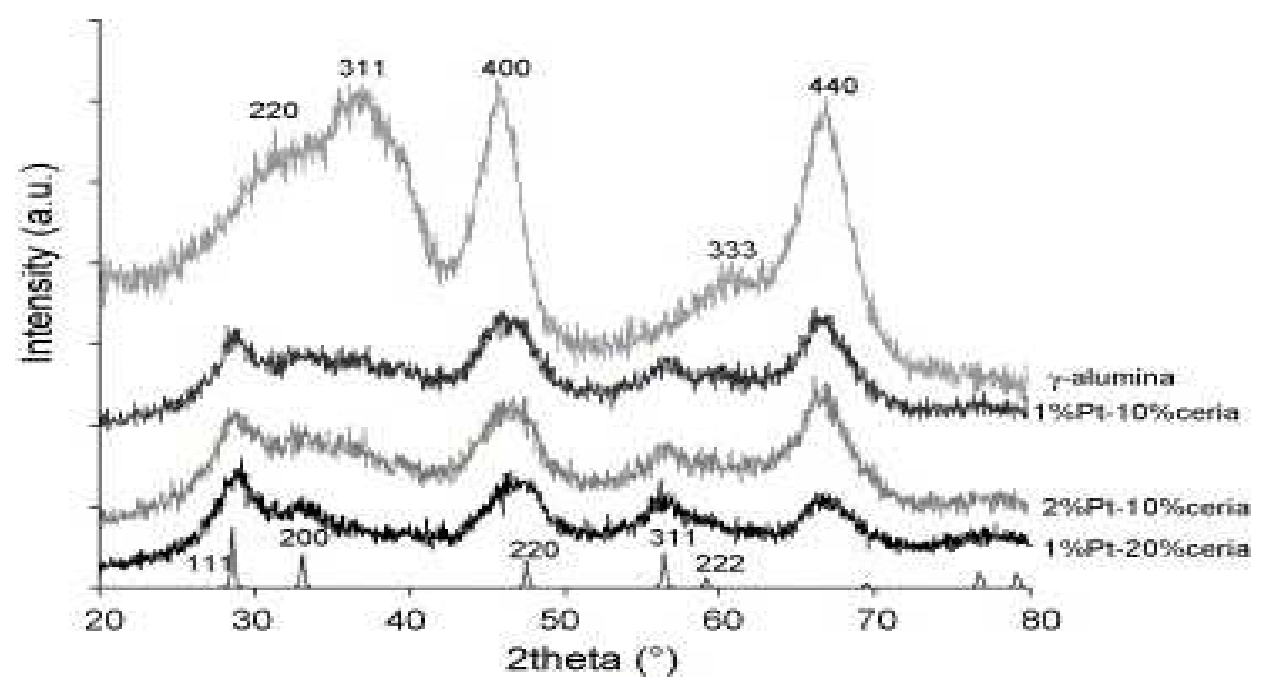

Fig. 5. Effect of hydrogen reduction on powder XRD patterns of the P2C1 catalyst sample $\left(\lambda_{\mathrm{Cu}}=0.154184 \mathrm{~nm}\right)$. Calculated lines of cubic $\mathrm{Pt}(0)$ have been added at the bottom of the figure.

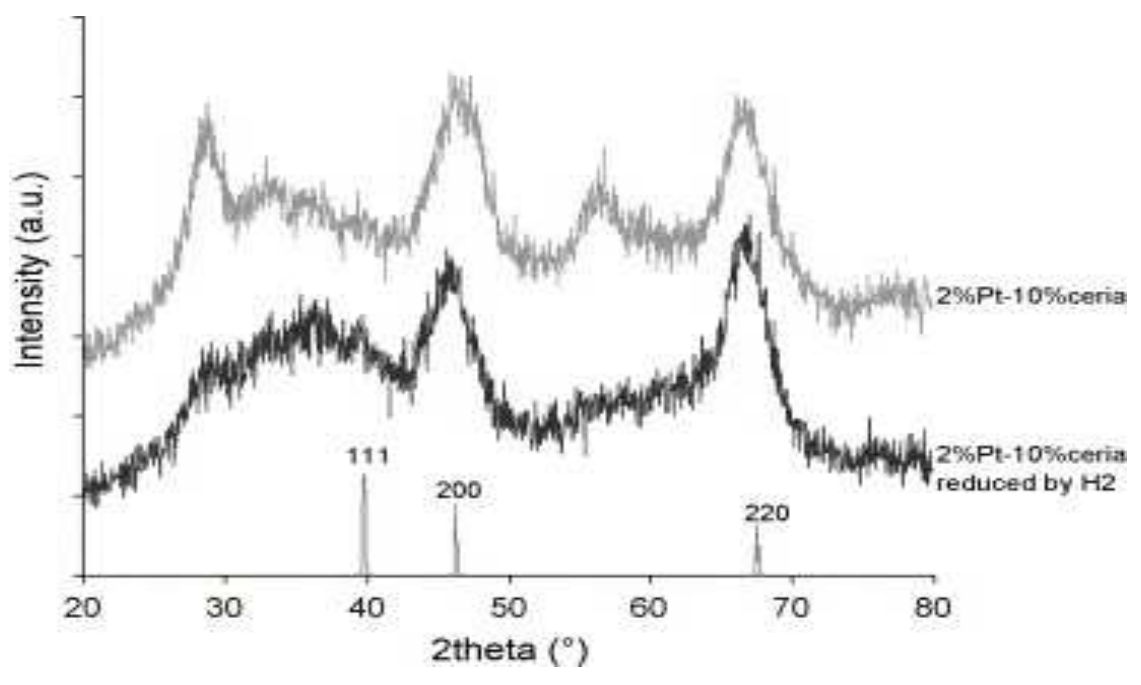

\subsection{Electron microscopy}

Measurements by transmission electron microscopy do not allow the proper detection of the platinum particles because of the lack of contrast between the ceria support and the metal crystallites [16] and [13] and instead high-resolution electron microscopy is needed [17]. This has been confirmed for both the 2 and $1 \mathrm{wt} . \%$ platinum samples in this study. 
Scanning electron micrographs of a catalyst containing $10 \%$ of $\mathrm{CeO}_{2}$ show the very porous texture of catalyst powders prepared from the sol-gel process (ig. 6). The scanning electron micrographs presented in Fig. 7 illustrates the effect of the addition of Rhodoviol ${ }^{\mathrm{TM}}$ on the texture of the coatings. These micrographs show, at different magnification, the surface of the coatings made consisting of $1 \%$ platinum on $20 \%$ ceria/alumina. The decomposition of Rhodoviol $^{\mathrm{TM}}$ creates a network with a large porosity.

Fig. 6. SEM of the $\mathrm{P} 2 \mathrm{C} 1$ catalyst sample calcined at $500{ }^{\circ} \mathrm{C}$ in air.

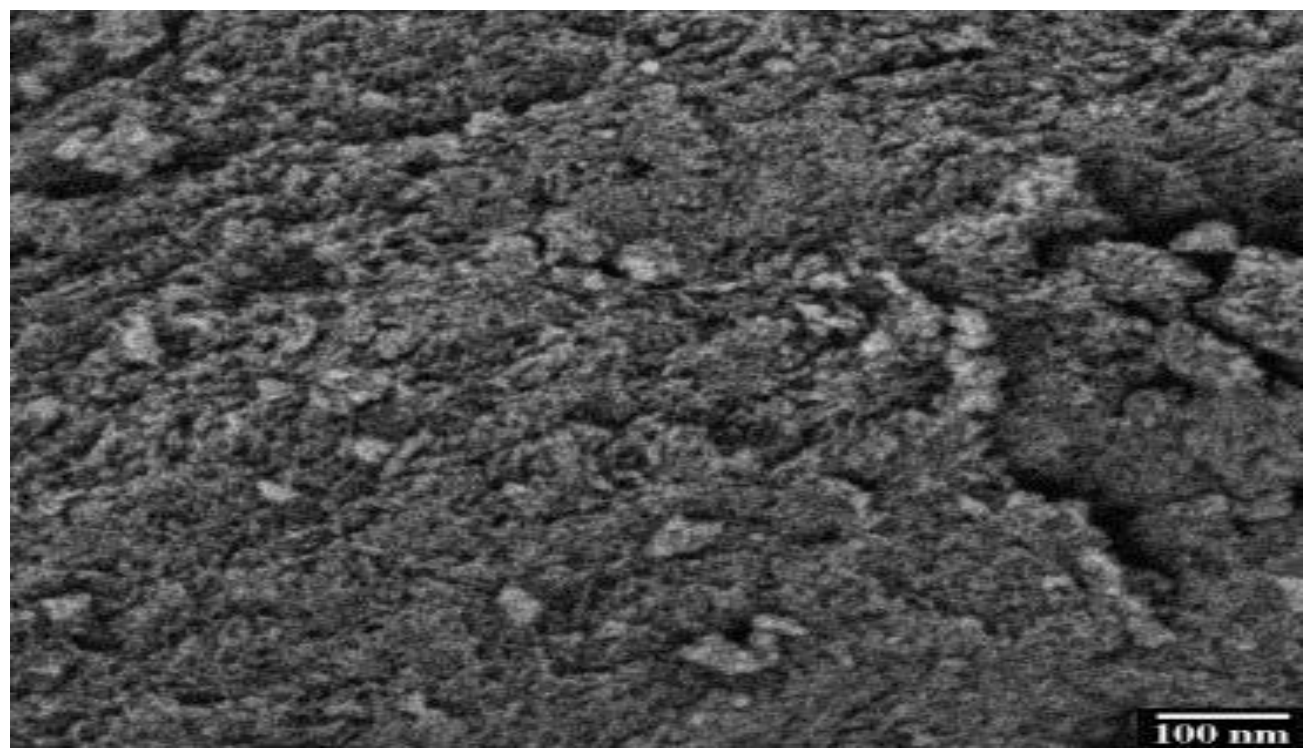



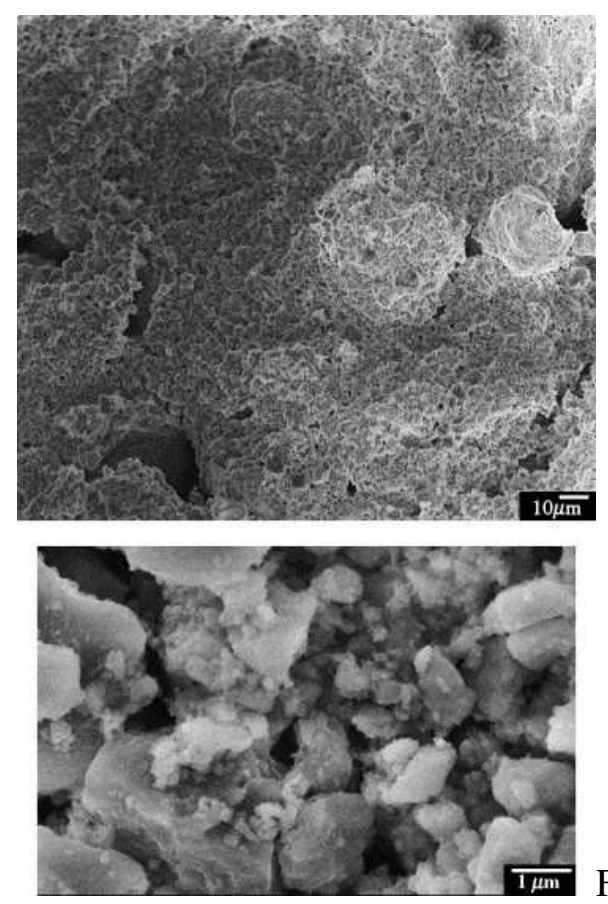

Fig. 7. SEM of the P1C2R sample coated on SS plates.

Fig. 8 shows the deposited catalyst layer inside the microstructure. It can be observed that the majority of the catalyst has been deposited on the bottom in a "triangular shape" with an equivalent particle diameter (that is the ratio of the surface area and the wetted perimeter) of $37 \mu \mathrm{m}$.

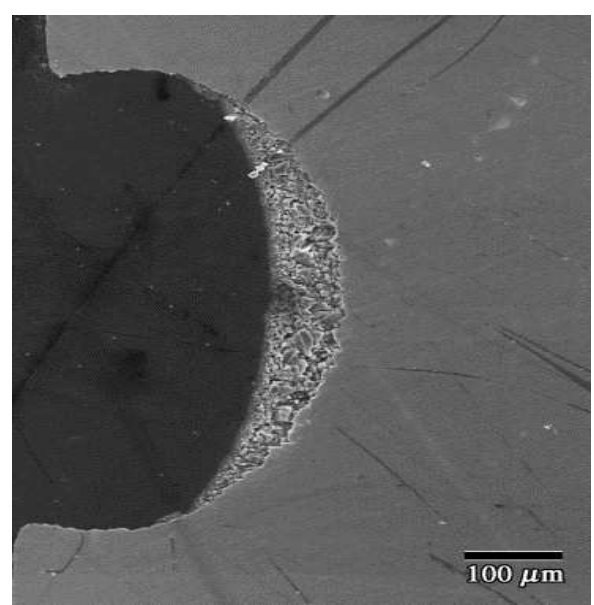

Fig. 8. SEM of the P2C1 catalyst sample deposited inside the microchannel. 


\subsection{Porosity and surface area by gas adsorption}

Nitrogen adsorption-desorption isotherms have been measured at $77 \mathrm{~K}$ on the powder catalysts. BET surface areas and pore volumes are reported in Table 3. The pore size distributions (PSD) presented in Fig. 9 show that the addition of platinum and/or ceria does not induce strong modifications to the porosity of $\gamma$-alumina. Addition of the platinum produces a slight increase in porous volume $(\approx 10 \%)$ but no change in the mean pore diameter $d_{\mathrm{h}}$. Addition of ceria induces both a decrease of the pore volume and of the mean pore diameter $d_{\mathrm{h}}$.

\section{Table 3.}

The effect of the addition of platinum and ceria on the porosity of alumina

\begin{tabular}{|l|l|l|l|}
\hline & $\boldsymbol{S}_{\text {BET }}\left(\mathbf{m}^{\mathbf{2}} \mathbf{g}^{-\mathbf{1}}\right)$ & Pore volume $\left(\mathbf{c m}^{\mathbf{3}} \mathbf{g}^{\mathbf{- 1}}\right)$ & Average pore diameter, $\boldsymbol{d}_{\mathbf{h}}(\mathbf{n m})$ \\
\cline { 1 - 2 } & 330 & 0.29 & 3.5 \\
\hline Alumina & 380 & 0.33 & 3.5 \\
\hline $1 \%$ Pt on alumina & 380 & 0.26 & 3.2 \\
\hline $1 \%$ Pt on 10\% ceria-alumina & 330 & & \\
\hline
\end{tabular}

The BET and pore volume are calculated from the nitrogen adsorption isotherms (the mean pore diameter $d_{\mathrm{h}}$ is calculated assuming a cylindrical pore geometry, $S_{\mathrm{BET}}$ being taken as the pore surface area, $d_{\mathrm{h}}=4 V / S$ ).

Fig. 9. Pore size distributions of alumina, Pt/alumina and Pt/ceria-alumina powder catalysts (calcinated at $500{ }^{\circ} \mathrm{C}$ under air) computed from $\mathrm{N}_{2}$ adsorption isotherm using BJH method. 


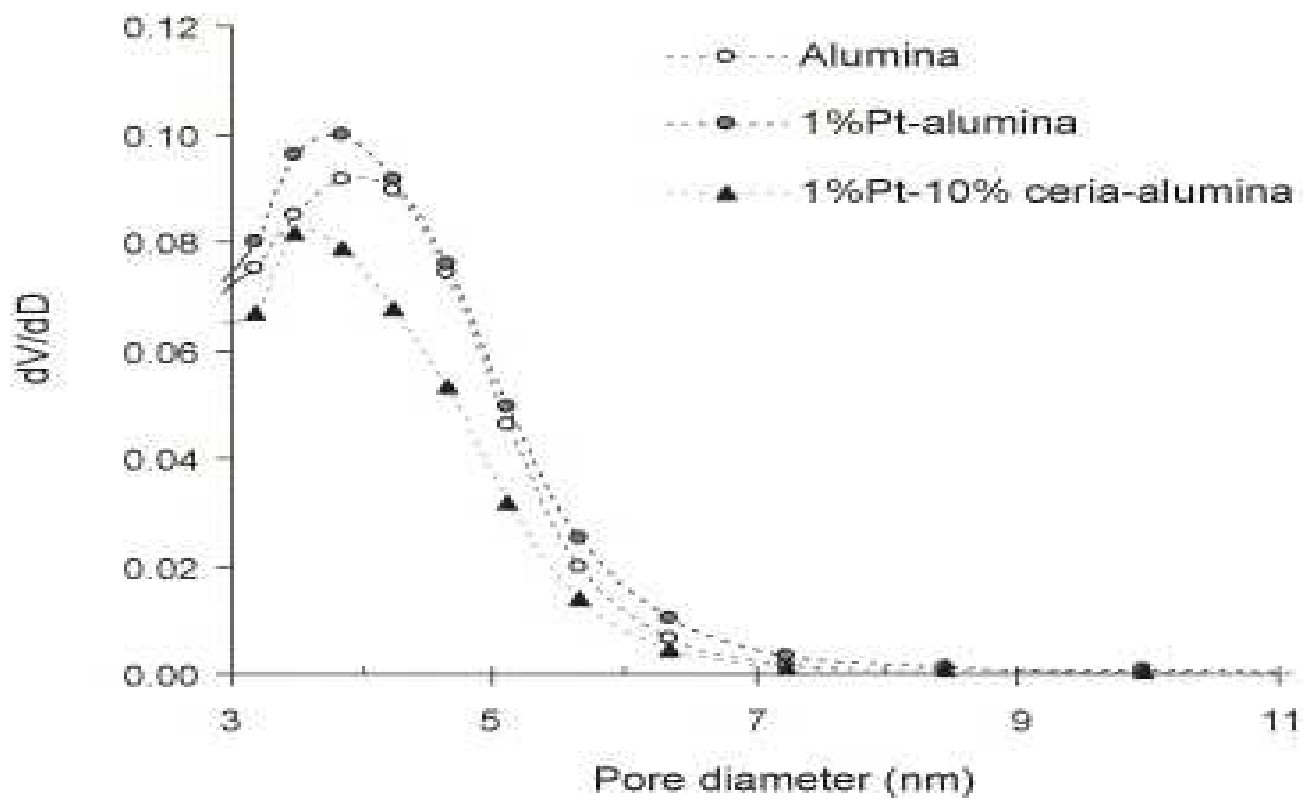

The surface area of the catalyst coatings on the microstructured platelets has been studied by gas adsorption. Due to the low surface areas involved, krypton has been used as the adsorbate. The surface enhancement factor (SEF), expressed in $\mathrm{m}^{2} / \mathrm{m}^{2}$, is defined as the ratio of the real surface area (as measured by gas adsorption) over the geometric surface. The values of SEFs, as calculated from surface area measurements by $\mathrm{Kr}$ adsorption on platelets coated with various catalysts, have been reported in Table 4 . In order to help the interpretation of the data, in the last column the ratio of the SEF to the coating thickness has also been calculated. From these results one can conclude that almost the complete catalyst surface area remains accessible to $\mathrm{Kr}$ even when the thickness of the layer increases. On the other hand, loading sols with catalyst powder does not decrease the surface area.

Table 4.

Surface enhancement factors (SEF) of platinum/ceria-alumina coatings

\begin{tabular}{|c|c|c|c|}
\hline & Coating thickness $(\mu \mathrm{m})$ & $\operatorname{SEF}\left(\mathbf{m}^{2} / \mathbf{m}^{2}\right)$ & $\operatorname{SEF}(\mu \mathrm{m})$ \\
\hline $1 \% \mathrm{Pt}+10 \% \mathrm{Ce}\left(\mathrm{NO}_{3}\right)_{3}$ & 1.1 & 1000 & 909 \\
\hline $1 \% \mathrm{Pt}+10 \% \mathrm{Ce}\left(\mathrm{NO}_{3}\right)_{3}+$ powder & 8.6 & 7700 & 895 \\
\hline $1 \% \mathrm{Pt}+10 \% \mathrm{Ce}\left(\mathrm{NO}_{3}\right)_{3}+$ powder & 12.3 & 10300 & 837 \\
\hline
\end{tabular}

\section{Discussion}


The data presented here confirm that platinum/ceria catalysts are indeed very active for the WGS reaction at temperatures above $250{ }^{\circ} \mathrm{C}$. The initial rate data measured for the $\mathrm{P} 2 \mathrm{C} 1$ sample corresponds approximately to a turnover frequency of $0.7 \mathrm{~s}^{-1}$ at $260{ }^{\circ} \mathrm{C}$. The initial rates do not vary to a large extent, within approximately a factor of 2 , with the different catalyst compositions. However, the turnover frequency for all samples is $0.6 \pm 0.1 \mathrm{~s}^{-1}$, assuming similar Pt dispersions for all samples. Apparently the amount of ceria does not alter the catalyst activity to a great extent. Moreover, no change in activity is observed by increasing the amount of the binder. Similarly, the initial rates obtained over the powder sample compare well with those obtained over the microstructured platelet. However, the data between powder and platelet deviate substantially at higher temperatures and conversion levels (Fig. 3). The conversion over the powder samples is lower than that of the platelets indicating that there might be diffusion limitation inside the pellets, as the pellet size $(250 \mu \mathrm{m})$ is substantially larger than the equivalent particle diameter of the catalyst layer $(37 \mu \mathrm{m})$ inside the microchannel. To verify this hypothesis, a simulation has been performed that takes into account explicitly the diffusion of matter inside the pellets. This simulation was based on a value of the average particle diameter of $250 \mu \mathrm{m}$, a tortuosity factor of 5 and the mean pore diameter and pellet porosity as calculated from the $\mathrm{N}_{2}$ adsorption data. Fig. 3 compares the experimental data and the simulation. It can be observed that at $260{ }^{\circ} \mathrm{C}$, the powder and platelet indeed give similar initial rates. Above this temperature the rates are lower due to diffusion limitation inside the pores, until the thermodynamic equilibrium is reached where the rate for the reverse water-gas shift is close to the forward rate and hence the overall rate is low. The model still overestimates the conversions in the medium temperature range. This can be due to an underestimation of the diffusion coefficients or the contribution of the smaller pores has been underestimated. The model evaluated the activity of the powder catalysts to be $60 \%$ of that of the thin layer catalysts deposited on the microstructured platelet. Thus the thin layer microstructured catalyst gives an optimum use of the platinum metal. This will be even worse for commercial catalysts in pellet form that usually have sizes in the millimeter range. In that case an eggshell design will be necessary to reduce the quantity of platinum needed. Recently a similar conclusion was reached for monolith-based catalysts [14].

\section{Conclusions}


Platinum/ceria/alumina catalysts have been prepared by a sol-gel method and coated in the microchannels of stainless steel platelets. The obtained coatings show good adherence and catalytic activity. Hardly any influence of the amount of ceria as well as the effect of a binder on the catalytic performance has been observed. The kinetics over these thin films has been described by a power law rate equation. An activation energy of $86 \mathrm{~kJ} / \mathrm{mol}$ has been found and at $260{ }^{\circ} \mathrm{C}$ the TOF corresponds to $0.6 \pm 0.1 \mathrm{~s}^{-1}$ for all investigated samples. The superior activity of the platelets compared to the powder samples is attributed to the diffusion limitations inside the powder pellets. Thus catalysts deposited on microstructured platelets lead to a better platinum utilization.

\section{Acknowledgements}

Part of this work has been funded by the EU "MINIREF" project (NNE5-2001-00056). IMM-Institut für Mikrotechnik Mainz GmbH is gratefully acknowledged for providing the microstructured platelets.

\section{$\underline{\text { References }}$}

D.C. Papageorgopoulos, M. Keijzer and F.A. de Bruijn, Electrochem Acta 48 (2002), p. 197.

W. Ruettinger, O. Ilinich and R.J. Farrauto, J. Power Sources 118 (2003), p. 61.

D. Andreeva, V. Idakiev, T. Tabakova and A. Andreeva, J. Catal. 158 (1996), p. 354.

A. Luengnaruemitchai, S. Osuwan and E. Gulari, Catal. Commun. 4 (2003), p. 215.

D. Andreeva, V. Idakiev, T. Tabakova, L. Ilieva, P. Falaras, A. Bourlinos and A. Travlos, Catal. Today 72 (2002), p. 51.

T. Shido and Y. Iwasawa, J. Catal. 141 (1993), p. 71.

O. Goerke, P. Pfeifer and K. Schubert, Appl. Catal. A: Gen. 263 (2004), p. 11.

T. Bunluesin, R.J. Gorte and G.W. Graham, Appl. Catal. B 15 (1998), p. 107. 
A. Goguet, F.C. Meunier, J.P. Breen, R. Burch, M.I. Petch and A. Faur Ghenciu, J. Catal. 226 (2004) (2), p. 382.

A. Holmgren, B. Andersson and D. Duprez, Appl. Catal. B 22 (1999), p. 215.

W. Ehrfeld, V. Hessel and H. Loewe, Microreactors, Wiley-VCH, Weinheim (2000).

B.E. Yoldas, Transparent activated non-particulate alumina and method of preparation, US Patent 3,941,719 (1976).

V. Perrichon, L. Retailleua, P. Bazin, M. Daturi and J.C. Lavalley, Appl. Catal. A: Gen. 260 (2004), p. 1.

Y. Schuurman, A.S. Quiney, G. Germani, C. Mirodatos, Proceedings of the Seventh World Congress of Chemical Engineering, in press.

J.M. Moe, Chem. Eng. Progr. 58 (1962), p. 33.

P.J. Levy and M. Primet, Appl. Catal. 70 (1991), p. 263.

S. Bernal, J.J. Calvino, M.A. Cauqui, G.A. Cifredo, A. Jobacho and J.M. RodriquezIzquierdo, Appl. Catal. A: Gen. 99 (1993), p. 1.

Corresponding author. Tel.: +334 724454 82; fax: +33 472445399 . 